\title{
A ESTÉTICA DO CHÁ
}

\section{Kensuke Tamai}

Palestra proferida em 19 de novembro de 1983, no Departamento dos Jovens da Escola Urasenke de São Paulo

Há uns dois meses, foi publicado num jornal da colônia, o artigo de um leitor sob o título: "A inutilidade da cerimônia do chá" Em sua crítica, percebia-se que nada havia de lógico ou de sistemático, e sim, notava-se nitidamente o lado emotivo. Pensei, contudo, que talvez exista um número razoável de pessoas de opinião similar. Creio que, entre os senhores, muitos já estejam a par do conteúdo desse artigo, porém, vou lê-lo a seguir, na sua íntegra.

"Será a cerimônia do chá uma arte? Será uma cultura? Toma-se o chá passando-se o chawan (tigela) de mão em mão, examina-se a base do chawan roçando-a levemente com a mão, e em seguida faz-se um cumprimento com muita polidez dizendo: "Foi uma esplêndida apresentação." $E$ todos esses movimentos numa morosidade irritante! Será que essa morosidade pode ser chamada de cultura? Tenho a impressão de que estamos sendo enganados por Sen Rikyū. Por que não se pode solver o chá de uma só vez? Por que, para se tomar um chawan de chá, há a necessidade de tanta cerimônia complicada?

A cerimónia do chá só pode ser considerada como um ato esnobe. Não digo que na sociedade de imigrantes seja desnecessária a cultura e a arte; mas que tal se procurássemos aquelas que sejam mais adequadas à nossa realidade? Gastar dinheiro e perder tempo nisso é desperdício de vida. Na colónia japonesa do Brasil há muitos chajin (adeptos da cerimónia do chá). Se lerem esta crítica sarcástica, deverão ficar furiosos. Mas, o que é sem sentido é sem sentido; o que é 
inútil, inútil. A cerimônia do chá, e o golfe são dois empreendimentos mais tolos da colônia japonesa."

A minha palestra de hoje talvez não seja uma resposta direta a este artigo, mas gostaria de pensar, junto com os senhores, o que significa a cerimónia do chá , abordando também os problemas inclu fdos nele.

Assim, logo no in ício do artigo, questiona-se: "Será a cerimónia do chá uma arte?" Trata-se de uma questão extremamente difícil. "O que é arte?" mais concretamente, "O que é arte e o que não é arte?" Como é do conhecimento dos senhores, até os dias de hoje, muitos dos filósofos e estetas do mundo têm discutido a questão, e há diversas teorias a respeito. Comumente dividimos a arte, conforme sua natureza, em quatro classes, a saber: artes plásticas como a escultura, a pintura, á arquitetura; artes de expressão corporal como o bailado e o teatro; arte sonora como a música; arte literária como a poesia, a novela, o drama. Até aqui não há problema, mas quando se trata da questão de podermos ou não considerar arte aquilo que está próximo às artes acima citadas, surge uma grande discussão. Por exemplo, é ou não é arte, produtos artísticos manufaturados semeIhantes às artes plásticas, como a cerâmica, os objetos laqueados, a tecelagem e a tintura de tecidos? Ainda, de acordo com o grande filósofo alemão Emmanuel Kant, a jardinagem, que tem uma relação intima com a arquitetura, é considerada arte; mas, um outro estudio. so opina o contrário, sustentando que o jardim é constitu ído principalmente de flores e de árvores, que estão sujeitas a intempéries da natureza e do mundo exterior, crescendo e transformando-se com o decorrer dos anos e das estações, não sendo possível o seu isolamento total. Neste caso, o que se diria entăo dos jardins japoneses que diferem completamente dos europeus, tendo como elementos principais a água, as pedras e as árvores de folha perene, denominados de jardins karesansui, como o de Ryōanji de Quioto, que possui uma pequena área de $200 \mathrm{~m}^{2}$, coberta de areias brancas e ornado com quinze pedras de tamanhos diversos?

Certa vez, acompanhei um pesquisador de arte americano a um jardim de pedras. Como ele se mostrou bastante admirado, pergunteiIhe: "Que tal, não é uma arte magn ífica?" Ele pensou por um instante e disse: "É artístico, porém não é arte. Realmente, a beleza deste jardim está na esplêndida composição das pedras e das areias brancas que quase não apresentam modificações, mas, quando do calor do verão, ou quando coberto de neve, a aparência deste jardim deve ser 
completamente diferente. Além disso, a paisagem que podemos ver além dos muros e a beleza das árvores conforme as estações devem influir muito neste jardim" Ou seja, como shakkei (paisagem emprestada) é insuficiente, portanto a jardinagem não é considerada uma arte verdadeira. Desse modo, definir o que é arte-é um problema muito delicado e difícil.

Então, será a cerimônia do chá realmente uma arte? Se assim for, em que lugar deve se posicionar? Antes de entrar no assunto, vamos fazer uma consideração sobre os três elementos que constituem a cerimônia do chá.

O primeiro fator importante na cerimônia do chá é que as pessoas reunidas passem momentos agradáveis. Em outras palavras, 0 importante é a sociabilidade. É certo que a sociabilidade possui um aspecto lúdico. Por isso, nos séculos $X V$ e $X V I$ as pessoas se reuniam para adivinharem o nome do chá que tomavam e premiavam-se os acertadores. Assim surgiu uma espécie de reunião de chá de jogata, que cada vez mais se intensificava. Em Nanbōroku (Memórias de Nanbō) que dizem conter os pensamentos e atitudes de Rikyü, anotados pelo seu discipulo Sōkei Nanbō, consta: "Tornando-se verdadeiras diversões seculares, o seu resultado vil é isso que ora presenciamos", fazendo o mestre Rikyū lamentar-se. Realmente nåo podemos negar que, de um modo geral, na palavra "sociabilidade" onde se subentende que "no relacionamento humano, elogiar convenientemente o interlocutor, não ferí-lo, tratar de tudo apropriadamente", nos deixa a impressão de um relacionamento um tanto superficial, năo havendo verdadeira sinceridade, e sim apenas relação passageira e fútil entre as pessoas. Porém, a verdadeira sociabilidade que existe na cerimônia do chá é o sentimento de solicitude, tanto da parte do visitante como do anfitrião. Em Kyaku no Shidai (Condiçőes do Visitante), Rikyū diz: "Tornar-se fútil" e "elogiar futilmente" sáo atos que nunca devem ser praticados. Também Fumai Matsudaira em Chasō (Fundamentos do Chá), elucida que "a cerimônia do chá é ser visitante sentindo-se na pessoa do anfitrião, ser anfitriăo sentindo-se na pessoa do visitante ".

A seguir, veremos o que é a verdadeira sociabilidade através de dois ou três episódios.

Em primeiro lugar, temos um episódio entre os famosos Hechikan e Rikyū. A respeito de Hechikan, ao qual já me referi no ano passado, quando discorri sobre Rikyū, talvez alguns dos senhores ainda se lembrem. Em sua vida, ele foi um verdadeiro chajin, não se su- 
jeitando a nenhuma autoridade de sua época. Em sua crítica sobre os últimos anos da vida de Rikyü, diz: "Rikyū, quando jovem, possuía uma alma pura e uma personalidade respeitável. Agora, porém, completamente mudado, tornou-se um ser fútil. Ele só conhece a glória e desconhece a decadência. Nesta curta existência humana, sofre pela fama e fortuna; é lamentável" Estas palavras tornaram-se muito famosas.

Num dia de verão, Hechikan convidou Rikyū para tomar chá na sua choupana de Yamashina em Quioto. Rikyū chegou na hora marcada, mas o portão estava trancado. Não tendo jeito, entrou pela portinhola do lado, e lá dentro, notou uma esteira estendida ligeiramente coberta de terra. No que pôs os pés, caiu num buraco e sujou toda a roupa. Nesse momento, apressadamente surgiu Hechikan e desculpando-se, conduziu -o ao quarto de banho. $O$ banho estava ótimo. Ao sair do banho, encontrou uma roupa nova à sua espera. A seguir, Hechikan convidou-o à sala de chá, e com toda a alma ofereceu-lhe o chá. Creio que os senhores podem imaginar a figura refrescada de Rikyū, apreciando o chá, de roupa limpa após retirar aquela toda suada do calor de verão e ter tomado um banho. Entretanto, Rikyū,antes de visitá-lo, já sabia por outrem da existência de uma armadilha. Rikyū caiu de propósito, cooperando na encenação de boa intenção de Hechikan; isto é, "fez-se visitante colocando-se na pessoa do anfitrião".

Outro episódio envolve Tadaoki Hosokawa, com o pseudônimo de Sansai, filho do famoso intelectual e chajin Yūsai Hosokawa. Sansai foi um samurai que havia tomado lições de chá com Rikyū. Sua esposa foi a católica Grácia que se suicidou aos 37 anos de idade. Sansai serviu a Yorinobu Tokugawa, décimo filho de leyasu Tokugawa. Certa ocasião, no fim de sua vida, Sansai, dirigindo-se a um dos súditos de Yorinobu, comentou: "O fim da minha vida está próximo, vou voltar a Kyūshū, minha terra natal, e talvez nunca mais possa retornar a Edc. Então, como última recordação de minha vida, gostaria de apreciar a caligrafia de Seisetsu, da propriedade do meu senhor" Seisetsu foi um monge zen chinês que viveu no in ício do século XII. Na época, sua caligrafia era muito apreciada entre os chajin. Yorinobu de bom grado concordou, marcando uma data e convidando-o para uma cerimônia de chá.

Nesse dia, ao entrar no chashitsu (sala de chá), Sansai notou que a caligrafia exposta não era de Seisetsu e sim de um outro monge zen. Sansai achou que a promessa não foi cumprida, mas sem tocar no 
assunto, tomou o seu chá. Quando já ia se retirando, após conversar na sala de estudos, esperava sentado no corredor aquele súdito ao qual havia confidenciado o seu desejo. Este retirou de uma caixa um caquemono e disse: "Hoje Yorinobu pretendia expor a caligrafia de Seisetsu como havia prometido, mas de acordo com suas palavras, por ter idade avançada, talvez não mais pudesse retornar a Edo; entretanto, o nosso amo retorquiu que o senhor ainda goza de mu ita saúde, e assim, certamente poderá retornar, e que ele faz questão do seu regresso. Foi este o motivo pelo qual ele deixou de expor o seu Seisetsu. No entanto, se o senhor fizer questão, poderá apreciá-lo à vontade aqui na sala de estudos" Diz-se que Sansai emocionou-se muito com esta demonstração de sensibilidade do seu senhor Yorinobu, quarenta anos mais novo que ele. Ele se fez anfitrião, "colocando-se na pessoa do visitante ".

Há um outro episódio. Sōkyū Tsuda era um chajin que juntamente com Rikyū foi líder dos chajin de Nobunaga Oda. Num dia de neve, ele visitou Rikyū no seu chashitsu. Ao aproximar-se sentiu um leve e agradável aroma de incenso que pairava no ar. Sōkyū, profundo conhecedor de incensos, logo percebeu que era o incenso Ranjakō, muito valioso. Recebido por Rikyū e conversando por alguns instantes, ouviu-se o ruído da porta do mizuya (um pequeno compartimento, anexo à sala de chá, onde se lavam os utensílios da cerimónia) que se abria. Rikyū explicou: "Para a cerimônia de hoje, encomendei a água do poço Samegai de Quioto. Porém, devido ao atraso, está sendo entregue agora. Para não desperdiçá-la, vou trocar a água do kama (caldeira)". Assim dizendo, saiu da sala com a caldeira. Sōkyū olhou para o ro (fogareiro embutido ao nivel do tatami) e notou um belo arranjo de canão, mas em silêncio retirou mais um carvão do cesto e acrescentou ao fogareiro. Depois limpou o daimoku (um suporte para colocar os utensílios da cerimônia) com habōki (pena). Logo depois, Rikyū trouxe a caldeira com água fresca. Sōkyū disse: "O aspecto do fogo estava magn ífico, porém, como o senhor trocou a água, achei que seria melhor ativar o fogo, e assim tomei a liberdade de acrescentar mais carvão" Mais tarde Rikyū comentou com os seus discípulos: "É de grande satisfação ferver a água e preparar o chá para visitantes desta natureza" Podemos dizer literalmente que, isto sim, é uma verdadeira reunião de chá: "Ser anfitriāo colocando-se na pessoa do visitante; servisitante colocando-se na pessoa do anfitrião"

Por outro lado, entre os elementos que constituem a cerimônia do chá, temos o espírito de treinamento, cuja natureza se opõe quase 
totalmente à sociabilidade acima citada. Como o hábito de tomar o chá nos tempos de Zen Budista é a origem da cerimônia do chá, ela possui desde o início o espírito de treinamento baseado nessa religião. A princípio, como consta no Muchūmondō do mestre Musō Kokushi, o chá tinha utilidade prática e medicinal. "Livra-se do torpor, desperta-se da sonolência, para auxiliar no treinamento" Mas aos poucos a cerimônia foi se desenvolvendo quanto ao aspecto espiritual, a ponto de realizarem charei, prática religiosa de caráter budista em que o chefe e as pessoas importantes do templo se sentam lado a lado para se servirem do mesmo tenshin (refeição leve) e tomarem o mesmo chá. Isto é considerado pelos sociólogos da religiao um ato de comunhão na alimentação, cujo fundamento se encontra na crença primitiva: "Comendo a mesma comida e tomando o mesmo líquido, os corpos se tornam um" A Santa Ceia da religiäo católica, a celebração após o ritual do xinto ísmo e sansankudo la troca de taças no casamento japonés) também possuem o mesmo significado. No artigo que apresentei no início da palestra criticava-se o ato de "tomar o chá passando de mão em māo" Talvez essa pessoa desconheça o sig. nificado da comunhão na alimentação que existe na arte do chá.

A essência da prática religiosa do chá que se realizava no templo zen foi sendo transmitida mesmo quando realizado longe do templo. em Nanbōroku, a que anteriormente me referi, consta: "A cerimônia do chá realizada numa pequena sala deve ser praticada de acordo com os primeiros ensinamentos de Buda. Sentir prazer no conforto da casa e uma alimentação sofisticada é pertencer ao mundo secular. Não tendo goteiras na casa, não passando fome, é o suficiente. Isto é o ensinamento de Buda e é a finalidade da arte do chá. Transportar a água, pegar a lenha, ferver a água, preparar o chá, ofertar a deus, aos demais e a si mesmo, ornamentar com flores, queimar incenso e aprender com a conduta de Buda. $O$ que não se pode deixar de observar aqui é a importância dada não só à auto-disciplina de acordo com o espírito budista, mas também à sociabilidade do chá, como diz um trecho: "Oferecer aos outros e também tomar"

O Zencharoku (Crônicas do chá Zen) de Sen Sōtan, neto de Rikyū, é o mais radical do ponto de vista do treinamento do chá. As palavras e os pensamentos dele foram anotados pelo seu discípulo Takuan, monge zen. Nesse compêndio consta o seguinte:

"O princípio fundamental do chá não leva em questão a boa ou a má qualidade do utensílio, nem discute o estado quando do seu uso, mas concentra-se unicamente no seu manejo, através do qual 
realiza-se o treinamento para apreciar a essência. Para elevar-se o próprio caráter através da prática do chá existe somente uma alternativa. E manejar os utensílios concentrando-se com probidade. Por exemplo, quando do uso do chashaku (colher utilizada na cerimónia do chá), concentrar-se nele com a pureza da alma, sem distrair-se por um só instante. Ao recolocá-lo também deve-se conservar o mesmo esta. do de espírito anterior. Isto não deve se limitar apenas ao chashaku, mas sim a qualquer outro utensílio" Resumindo o que foi dito, temos: "Conforme a prática do treinamento do chá, o homem pode alcançar o limite máximo do bem. Para isso é muito importante o espírito para o manejo dos utensílios. Quando do seu uso, é preciso livrar-se de toda a maldade e resguardar em absoluto as normas do Budismo ". O importante aqui é: 'No treinamento resguardar em absoluto a ética do chá" e isto talvez seja outro fator formal importante para constituir a cerimônia do chá.

A respeito da etiqueta no chadō, como se vê em Cha-no-yu Taisei Hishō (Escritos sobre o bom êxito no Cha-no-yu): "A cerimônia do chá lega-nos vários ensinamentos através da sua forma respeitosa de preparar o chá, o modo de colocar, o modo de relacionar", o que implica no princípio da ordem - quer dizer, é a regra adequada para se realizar algo do modo mais racional e belo - assim se faz a estrutura da cerimônia do chá. Por isso nos livros de introduçăo à cerimónia do chá, como Bunrui Söjinboku, que se diz transmissor das palavras de Takeno Jōō, embora apresentando pequenas variaçōes conforme a época, todos descrevem minuciosamente as formas de cortesia do anfitrião e do visitante. Por parte do anfitrião, as partes mais importantes são o manejo dos utensflios, a colocação, a ornamentação e o preparo do chá; e por parte do visitante, o ingresso pelo roji (jardim), a entrada na sala e os movimentos dentro da sala. Observando os livros didáticos como Chadōbenmōshō, escrito pelo discípulo de Sen Sōtan a quem me referi anteriormente, estes descrevem com extrema minúcia o método da cortesia, o que nos faz pensar que somente estas formas de cortesia são a substáncia do chá. Porém este sistema de cortesia não passa de um dos elementos que compóem a cerimónia do chá que, sem a complementação da sociabilidade e do espírito de treinamento, não adquire vida.

Certo dia, Rikyū passou na casa de seu discípulo Chikuan Kanbayashi. Este, com a presença do seu mestre, que muito admirava, ficou completamente emocionado e de tanta alegria a mão Ihe tremia fazendo com que derrubasse o chasen (batedeira de bambu) e dei- 
xasse cair o chashaku de cima do natsume (pote para chá). Os outros discípulos que acompanhavam o mestre riram, mas, mais tarde, Rikyū repreendeu-os dizendo: "A cerimonia do chá de hoje foi o melhor de todo o Japão. Malogrou por querer preparar o chá antes que a água esfriasse e também não conseguiu preparar o chá com perfeiçào. Mas aquele espírito profundo, compenetrado de corpo e alma, é um ato grato a que raramente podemos presenciar, e se vocês riram ao observar só a parte externa é porque vocês não conhecem a verdadeira arte do chá" Ainda, Rikyú em Nanbōroku, criticando o famoso chajin da época Sōkyū Naya, disse, com convicção: "Quando da apresentação da arte de preparar o chá, o pote de Sōkyū é de uma magnificência sem defeitos. Por isso, certa época, Hideyoshi tinha maior consideração por ele do que a mim. Mas não há verdadeira compenetraçào da alma no chá de Sōkyū. Eis a razão de ele ter sido. dispensado por Hideyoshi posteriormente "

Assim, a cerimônia do chá requer a harmonia de três elementos: ritualidade, sociabilidade e treino, isto é, estrutura, corpo e alma. Ainda, só quando sobre isso é acrescida a criatividade artística surge a verdadeira e perfeita cerimonia do chá.

Se considerarmos a cerimonia do chá uma arte, em qual dos quatro tipos de arte que mencionei no in ício da palestra, poderia ser enquadrada? Em primeiro lugar, a cerimônia do chá difere da poesia e do romance; e tampouco parece pertencer à classe da pintura, da escultura ou da arquitetura; assim como difere da música. Como conclusão, resta apenas a arte de expressão corporal como o bailado e o teatro. Nesta também se inclui o teatro $N \bar{o}$. E verdade que em grande chakai (reunião de chá), as damas impecavelmente vestidas preparando o chá com ar sério lembram o palco de Nō ou os movimentos de um shimai (bailado do teatro Nö) em um zashiki (sala de tatami). E claro que se no temae (preparo do chá), os movimentos forem exagerados ou a exibição se tornar muito teatral, há algo de errado; mas a verdade é que no próprio temae existem movimentos que se assemeIham aos do bailado e que a cerimônia do chá, como o teatro, é uma representação através dos movimentos do corpo.

No entanto, a cerimônia do chá difere grandemente do bailado e do teatro, embora enquadrada neste tipo de arte, pois no bailado ou no teatro o artista e os espectadores estão nitidamente separados, mas no chá isto não acontece. $O$ visitante observa $O$ arranjo da sala, aprecia o temae do anfitrião, e este também observa o movimento do visitante e o modo de se tomar o chá, formando juntos um todo. 
A segunda diferença trata-se da representação do chá que possui um caráter que parece ser inadequado à própria palavra "representação" Isto porque o chá não possui a moldura de um palco como no bailado ou no teatro. A cerimonia do chá, sem o isolamento completo do cotidiano, se realiza no chashitsu que é um espaço da vida cotidiana, e não dentro de um palco, assim construindo um cenário do cotidiano que seria preparar e tomar um chá. Por isso, os movimentos corporais da cerimònia do chá não são uma mímica, como no bailado ou no teatro, nem uma expressão corporal que busca apenas a beleza da forma pura, isolada do cotidiano. Mas todos os movimentos de preparar e tomar o chá seguem obrigatoriamente as regras, não sendo permitido agir livremente, como na vida cotidiana. Porém, como temae é a ordenação estética dos atos de preparar o chá, tomar o chá ou oferecer a terceiros, pode ser aplicado na vida cotidiana. Estas regras devem ser obedecidas, mas as pessoas que já se especializaram não praticam a cerimônia como as regras pedem. Acontece também de modificarem velhas regras, inovando-as. Daí talvez a razão de terem surgido novas escolas.

Como foi explanado anteriormente, a cerimônia do chá diferencia-se do bailado e do teatro por ter o seu isolamento artístico deficiente. $O$ isolamento artístico significa distinção clara entre o campo da arte e os outros campos, rompendo conscientemente as suas relações com o mundo da natureza e do cotidiano para, através disso, esclarecer que o mundo da arte possui independência e autonomia próprias. Deve-se pensar que aí está o significado da moldura do quadro, da encadernação, da base da escultura ou ainda, do palco do bailado ou do teatro.

Entretanto, para se entrar na sala de chá, as pessoas devem dirigirse para um roji silencioso, purificar a boca e lavar as mãos no tsukubai (vaso de pedra com água). Esta é a passagem do espaço da vida cotidiana para um outro mundo que é o de chá. Por isso, árvores com galhos bonitos e flores vistosas que distraem os visitantes sao evitadas. A porta de entrada à sala de chá é estreita. Esta também é uma passagem para um mundo diferente. A sala de chá para onde são conduzidos ignora a liberdade da tradição arquitetônica japonesa. A sua localização, o seu tamanho, o corte da janela, o aproveitamento da luz, a entrada, tudo é isolado da vida cotidiana, de modo que nem da janela pode se ver o jardim formando um mundo à parte. Os utensílios usados para o chá não são aqueles usados no cotidiano, adotando-se aqueles que demonstram ser mais cerimoniosos, separando-se 
assim, do convívio diário. Talvez seja por isso mesmo que freqüentemente utilizam-se de chawan deformado, que não se costuma usar no dia-a-dia. É certo que temae que aqui se realiza teve sua origem na racionalização dos atos praticados na vida cotidiana. Porém, isto, uma vez transformando-se em regra, toma forma independente como cerimônia pública, isolando-se do cotidiano. E assim, como se diz no ambiente de wabi e sabi (pensamentos éticos e estéticos em que se baseia a cerimônia do chá), centralizando-se no temae, são realizadas, entre $O$ anfitrião e $o$ visitante, cenas improvisadas que contêm também elementos do bailado.

Certamente, a cerimônia do chá, comparada com o bailado ou o teatro, que são artes de expressão corporal, talvez seja pobre em seu isolamento artístico. Porém, como disse anteriormente, no mínimo pode ser considerada como extraordinariamente artística, mesmo não sendo arte propriamente dita. Pode-se considerar que ela se posiciona no mesmo nível do jardim de pedras do Ryōanji, dentro das artes plásticas.

Finalmente, acho que devo uma resposta ao artigo que citei no in ício da palestra. Se o autor não necessita da sociabilidade, do cerimonial, da disciplina do chá e do seu caráter artístico, considerando o chá como simples bebida como o guaraná e a cerveja, então deve tomá-lo à sua vontade, num só gole. 